\section{RMD Open}

Rheumatic \&

Musculoskeletal Diseases

\title{
Hyperechogenic intimal lesions and wall thickness of the temporal and facial arteries in elderly patients with arterial occlusions of the eye
}

\author{
Michael Czihal (D) , ${ }^{1}$ Anton Köhler, ${ }^{1}$ Ilaria Prearo, ${ }^{1}$ Ulrich Hoffmann, ${ }^{1}$ \\ Hendrik Schulze-Koops (1) , ${ }^{2}$ Claudia Dechant, ${ }^{2}$ Siegfried G Priglinger, ${ }^{3}$ \\ Marc J Mackert, ${ }^{3}$ Christian Lottspeich ${ }^{4}$
}

To cite: Czihal M, Köhler A, Prearo I, et al. Hyperechogenic intimal lesions and wall thickness of the temporal and facial arteries in elderly patients with arterial occlusions of the eye. RMD Open 2021;7:e001688. doi:10.1136/ rmdopen-2021-001688

- Additional supplemental material is published online only. To view, please visit the journal online (http://dx.doi.org/10. 1136/rmdopen-2021-001688).

Received 22 April 2021 Accepted 2 September 2021

Check for updates

(C) Author(s) (or their employer(s)) 2021. Re-use permitted under CC BY-NC. No commercial re-use. See rights and permissions. Published by BMJ.

For numbered affiliations see end of article.

Correspondence to Dr Michael Czihal; michael.czihal@med.unimuenchen.de

\section{ABSTRACT}

Objective To determine the association of arteriosclerosis, characterised by hyperechogenic intimal lesions (HIL), with wall thickness of the temporal and facial arteries in elderly patients with ocular arterial occlusions.

Methods Patients suffering from non-arteritic ocular perfusion disorders were included. High-resolution compression sonography $(18 \mathrm{MHz}$ ) images of the temporal arteries (frontal and parietal branch at the upper margin of the auricle) and facial arteries (at the crossing point of the artery over the mandible) were analysed for the presence of HIL (grade 0: absent; grade 1: moderate; grade 2: severe). Characteristics of patients with and without evidence of HIL > grade 1 were compared.

Results In total, 330 cranial artery segments of 55 patients were analysed. HIL $\geq$ grade 1 was present in $13.0 \%$ of all artery segments and in $38.1 \%$ of all patients. Patients with HIL $\geq$ grade 1 in at least one arterial segment displayed significantly increased maximum wall thickness of the temporal arteries $(0.62 \pm 0.23 \mathrm{~mm}$ vs $0.50 \pm 0.13 \mathrm{~mm} ; \mathrm{p}<0.01)$ and facial arteries $(0.71 \pm 0.20 \mathrm{~mm}$ vs $0.54 \pm 0.19 \mathrm{~mm} ; p=0.01)$. Patients with at least one temporal or facial artery segment with HIL were older, more often male and more frequently suffered from diabetes mellitus.

Conclusion The presence of HIL goes along with a significantly increased wall thickness of the temporal and facial arteries. These findings should be considered when interpreting the results of sonography of the cranial arteries in the diagnostic workup of suspected giant cell arteritis.

\section{INTRODUCTION}

Sonography of the superficial temporal arteries and optionally of the facial arteries nowadays is the first-line imaging test in suspected cranial giant cell arteritis (cGCA). ${ }^{1}$ According to a meta-analysis informing the current imaging recommendations of the EULAR, sensitivity and specificity of the 'non-compressible Halo sign' for the

\section{Key messages}

What is already known about this subject?

- Cranial artery wall thickness is an important diagnostic criterion for the diagnosis of cranial giant cell arteritis (CGCA) by high-resolution sonography.

- Cranial artery wall thickness may be influenced by cardiovascular risk.

What does this study add?

- Focal arteriosclerotic lesions of the cranial (temporal and facial) arteries are commonly present in patients above the age of 50 suffering from arterial occlusions of the eye.

- Wall thickness of the cranial (temporal and facial) arteries is increased in the presence of focal arteriosclerotic lesions.

How might this impact on clinical practice or future developments?

- These findings advocate establishment of age, sex and cardiovascular risk adapted cut-off values of cranial artery wall thickness for the diagnosis of cGCA as well as clinical probability-based decisionmaking for vascular imaging in suspected CGCA.

diagnosis of cGCA are $77 \%$ and $96 \%$, respectively. ${ }^{2}$ Recently, high-resolution sonography protocols aiming on wall thickness measurements of the cranial arteries have been tested, yielding very promising diagnostic accuracy. ${ }^{3-6}$ However, arteriosclerosis is an important pitfall in sonographic assessment of the cranial arteries for suspected cGCA. ${ }^{7}$ Arteriosclerotic changes can be visualised by sonography and are typically characterised by focal or diffuse hyperechogenic intimal lesions (HIL). The histopathological correlate of such arteriosclerotic lesions is dense fibrous intimal thickening, in part accompanied by calcium deposition (sonographically 
identifiable by dorsal acoustic shadowing).$^{8}$ However, the extent of such HIL of the cranial arteries in subjects above the age of 50 and their impact on the diagnostic yield of sonography of the cranial arteries for the diagnosis of cGCA is unknown. The present study aimed to assess the association between HIL and temporal artery wall thickness in a cohort of elderly patients with ocular perfusion disorders of non-arteritic aetiology.

\section{PATIENTS AND METHODS}

Given the retrospective nature of the study written informed consent of the individual patients was waived. From a cohort of patients suffering from non-arteritic central retinal artery occlusion (CRAO), branch retinal artery occlusion (BRAO) or non-arteritic anterior ischaemic optic neuropathy (NAION) referred for vascular ultrasound between January 2016 and December $2019,{ }^{9}$ those patients with complete ultrasound imaging of the superficial temporal and the facial arteries were eligible for the present study. All cases were independently reviewed by an experienced rheumatologist $(\mathrm{CD})$, ophthalmologist (MJM) and angiologist (MC) to establish the final clinical diagnosis. Patients fulfilling diagnostic criteria of cGCA, as outlined previously, were excluded from the analysis (online supplemental table 1). ${ }^{39}$

Vascular sonography was performed according to a predefined protocol, including high-resolution B-mode compression sonography (HRCS) of the superficial temporal arteries and facial arteries with an $18 \mathrm{MHz}$ linear hockey stick transducer (LOGIQ E9, General Electrics, Milwaukee, Wisconsin, USA). ${ }^{2}$ Wall thickness measurements of the frontal and parietal branches of the superficial temporal arteries were performed at the upper margin of the auricle, and wall thickness of the facial arteries was measured at the crossing point of the artery over the mandible. ${ }^{4}$ After collapse of the arterial lumen due to transducer-induced compression, the intima-media thickness (IMT) is measured in the transversal plane. As the IMT values of the near and far arterial wall are summed up, values are approximately twice as high as those obtained with conventional measurement of the far wall IMT in the longitudinal plane. ${ }^{349} \mathrm{In}$ a previous study we established cut-off of temporal artery wall thickness of $\geq 0.7 \mathrm{~mm}$ for the diagnosis of cGCA. ${ }^{4}$

Stored HRCS images with transversal sections of the above-mentioned vessel segments were reviewed for the presence of HIL. HIL were classified according to visual rating as follows: grade 0 , no visible hyperechogenic structures at the luminal border of the intima-media complex; grade 1, unequivocal linear or spot-like hyperechogenic structures at the luminal border of the intimamedia complex, visible with and without compression; grade 2, marked hyperechogenic linear or spot-like structures of the intima-media complex at the luminal border of the intima-media complex, with or without acoustic shadowing (figure 1).
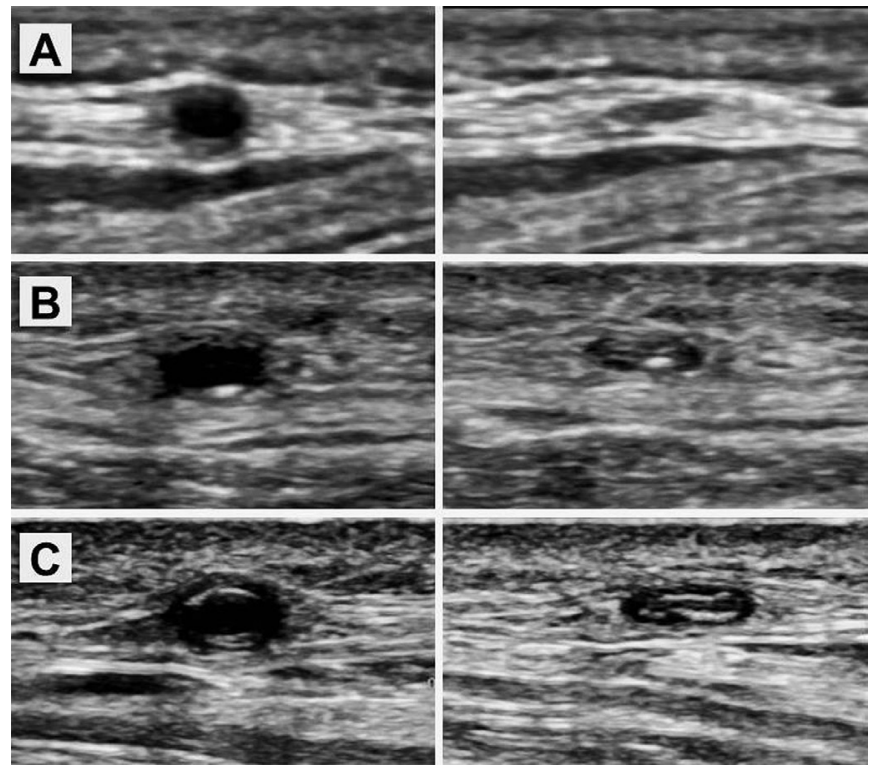

Figure 1 Examples of HIL of the cranial arteries with and without compression. Temporal artery branch without HIL (grade 0) (A), with focal HIL (grade 1) (B) and with marked HIL (grade 2) (C). The intima-media complex is markedly thickened in the artery displayed in panel (C) not distinguishable from vasculitic wall thickening. HIL, hyperechogenic intimal lesion.

Characteristics of patients with and without evidence of HIL of the temporal and/or facial arteries were compared using univariate significance tests. HIL of the temporal and facial artery segments were correlated with wall thickness, as measured by HRCS, ${ }^{4}$ and with age and cardiovascular risk profile according to the $\mathrm{CHA}_{2} \mathrm{DS}_{2}-$ VASc score (Spearman's rank correlation). The relative effects of age, sex and the presence of HIL on arterial wall thickness were explored by multiple linear regression analysis. For statistical analysis, SPSS V.25.0 was applied. Two-sided $\mathrm{p}$ values $<0.05$ were considered significant.

\section{RESULTS}

Fifty-five patients were included in the analysis, comprising 13 patients with BRAO as well as 21 patients with CRAO and NAION, respectively. The clinical characteristics of the cohort are listed in table 1 . None of the patients fulfilled diagnostic criteria of cGCA. Three patients had a history of polymyalgia rheumatica (PMR) but did not suffer from PMR symptoms at the time of diagnosis. Temporal artery biopsy was performed in eight $(14.5 \%)$ patients, with negative histology in all.

In the per-segment analysis, $38(11.5 \%)$ and $5(1.5 \%)$ out of 330 examined cranial artery segments exhibited HIL grade 1 and grade 2, respectively. While facial artery segments were more commonly affected by HIL (20\% vs $9.6 \%$ in temporal artery segments), HIL grade 2 were found only in temporal artery segments $(n=5,2.3 \%)$. HIL $\geq$ grade 1 of the respective arterial segments were significantly but only weakly correlated with temporal artery wall thickness (rho: $0.31, \mathrm{p}<0.01$ ) and facial artery 
Table 1 Overall cohort characteristics (per patient analysis) and comparison of individuals with and without HIL

\begin{tabular}{|c|c|c|c|c|}
\hline Variable & $\begin{array}{l}\text { Overall cohort } \\
\mathrm{n}=55\end{array}$ & $\begin{array}{l}\text { HIL present } \\
\mathrm{n}=21\end{array}$ & $\begin{array}{l}\text { No HIL } \\
\mathrm{n}=34\end{array}$ & $P$ value \\
\hline Age, years $($ mean $\pm S D)$ & $72.4 \pm 10.6$ & $76.0 \pm 9.5$ & $69.7 \pm 10.5$ & 0.07 \\
\hline Male sex, \% & 52.7 & 71.4 & 41.2 & 0.05 \\
\hline $\mathrm{C}$ reactive protein, $\mathrm{mg} / \mathrm{dL}($ mean $\pm \mathrm{SD})$ & $0.8 \pm 1.1$ & $0.6 \pm 0.5$ & $1.0 \pm 1.3$ & 0.77 \\
\hline Erythrocyte sedimentation rate, $\mathrm{mm}$ per 1 hour (mean \pm SD) & $18 \pm 29$ & $15 \pm 20$ & $16 \pm 23$ & 0.67 \\
\hline Type of arterial perfusion disorder (\%) & & & & 0.47 \\
\hline CRAO & 38.2 & 47.6 & 32.4 & \\
\hline BRAO & 23.6 & 23.8 & 23.5 & \\
\hline NAION & 38.2 & 28.6 & 44.1 & \\
\hline $\mathrm{CHA}_{2} \mathrm{DS}_{2}-\mathrm{VASc}$ score $($ mean $\pm \mathrm{SD})$ & $3.5 \pm 1.8$ & $3.8 \pm 1.7$ & $3.1 \pm 1.8$ & 0.09 \\
\hline Arterial hypertension, \% & 80 & 90.5 & 73.5 & 0.17 \\
\hline Diabetes mellitus, \% & 30.9 & 47.6 & 20.6 & 0.07 \\
\hline $\begin{array}{l}\text { Maximum common carotid artery intima media thickness, } \\
\text { mean } \pm \text { SD }\end{array}$ & $0.90 \pm 0.18$ & $0.94 \pm 0.17$ & $0.87 \pm 0.18$ & 0.18 \\
\hline Carotid artery plaque, $\%$ & $49(89.1)$ & $20(95.2)$ & $29(85.3)$ & 0.39 \\
\hline $\begin{array}{l}\text { Carotid artery stenosis } \\
\geq 50 \%, \%\end{array}$ & $11(20)$ & $5(23.8)$ & $6(17.6)$ & 0.73 \\
\hline Carotid artery calcification with acoustic shadowing, \% & $31(56.4)$ & $16(76.2)$ & $15(44.1)$ & 0.03 \\
\hline Maximum temporal artery wall thickness, $\mathrm{mm}($ mean $\pm \mathrm{SD})$ & $0.55 \pm 0.18$ & $0.62 \pm 0.23$ & $0.50 \pm 0.13$ & $<0.01$ \\
\hline Maximum facial artery wall thickness, $\mathrm{mm}(\operatorname{mean} \pm \mathrm{SD})$ & $0.61 \pm 0.22$ & $0.71 \pm 0.20$ & $0.54 \pm 0.19$ & 0.01 \\
\hline
\end{tabular}

All significant $p$-values are indicated in bold.

BRAO, branch retinal artery occlusion; CRAO, central retinal artery occlusion; HIL, hyperechogenic intimal lesion; NAION, non-arteritic anterior ischaemic optic neuropathy.

wall thickness (rho: $0.29, \mathrm{p}<0.01$ ). Mean wall thickness was $0.45 \pm 0.15 \mathrm{~mm}, 0.59 \pm 0.17 \mathrm{~mm}$ and $0.86 \pm 0.27 \mathrm{~mm}$ in temporal segments with HIL grade 0,1 and 2, respectively $(\mathrm{p}<0.01)$. Mean wall thickness was $0.53 \pm 0.2 \mathrm{~mm}$ and $0.65 \pm 0.15 \mathrm{~mm}$ in facial artery segments with HIL grade 0 and grade 1 , respectively $(\mathrm{p}<0.01)$. Overall, wall thickening $\geqq 0.7 \mathrm{~mm}$ was observed in $12.7 \%$ and $17.3 \%$ of temporal and facial artery segments, respectively.

In the per-patient analysis, $21(38.1 \%)$ patients had HIL $\geqq$ grade 1 in at least one segment of the temporal and/or facial arteries. In nine patients, all of whom were males aged $\geqq 70$ years, HIL $\geq$ grade 1 were visible in two or more arterial segments. Two male patients (79 and 89 years old, both diabetics suffering from CRAO) exhibited HIL grade 2 in two and three segments, respectively. Acoustic shadowing in association with HIL in at least one vessel segment was documented in two male patients, both diabetics (3.6\% of the study population).

Patients with at least one temporal or facial artery segment affected by HIL were more commonly male $(71.4 \%$ vs $41.2 \%, p=0.05)$ and more frequently suffered from diabetes mellitus $(47.6 \%$ vs $21.6 \%, p=0.07)$. Mean age was $76.0 \pm 9.5$ years in patients with HIL versus $69.7 \pm 10.5$ years in patients without HIL $(\mathrm{p}=0.07)$. Mean $\mathrm{CHA}_{2} \mathrm{DS}_{2}$-VASc score was $3.8 \pm 1.7$ in patients with HIL versus $3.1 \pm 1.8$ in patients without HIL $(p=0.09)$. While there were no meaningful differences in the prevalence of carotid artery plaques, carotid artery calcification with acoustic shadowing was significantly more common in patients with HIL $(\mathrm{p}=0.03)$.

The maximum cranial artery wall thickness was significantly higher in patients with at least one cranial artery segment affected by HIL (temporal arteries: $0.62 \pm 0.23 \mathrm{~mm}$ vs $0.50 \pm 0.13 \mathrm{~mm} ; \mathrm{p}<0.01$; facial arteries: $0.71 \pm 0.20 \mathrm{~mm}$ vs $0.54 \pm 0.19 \mathrm{~mm} ; \mathrm{p}=0.01$, figure 2 ). Maximum temporal artery wall thickness $\geqq 0.7 \mathrm{~mm}$ was present in $20 \%$ of patients but was rarely found in patients without evidence of temporal artery HIL (6.8\%). By contrast, wall thickening $\geqq 0.7 \mathrm{~mm}$ was very common in patients with HIL in at least temporal artery segment $(45.5 \%, \mathrm{p}<0.01)$. Maximum facial artery all thickness $\geqq 0.7 \mathrm{~mm}$ was detected in $25.5 \%$ of patients (no evidence of HIL: $16.2 \%$; HIL present: $44.4 \% ; \mathrm{p}=0.02)$. Multiple linear regression analysis revealed that age $\geqq 70(p=0.03)$ and male sex $(p<0.01)$ were independently associated with arterial wall thickness of the temporal and facial arteries, whereas HIL $(\mathrm{p}=0.13$ and 0.43 , respectively) were not.

\section{DISCUSSION}

In our study on elderly patients with non-arteritic arterial perfusion disorders of the eye, arteriosclerotic changes of the temporal and/or facial arteries (characterised as HIL by HRCS) were frequently found. Although not independently associated with increased cranial artery wall thickness, HIL can be interpreted as indicator lesions of 

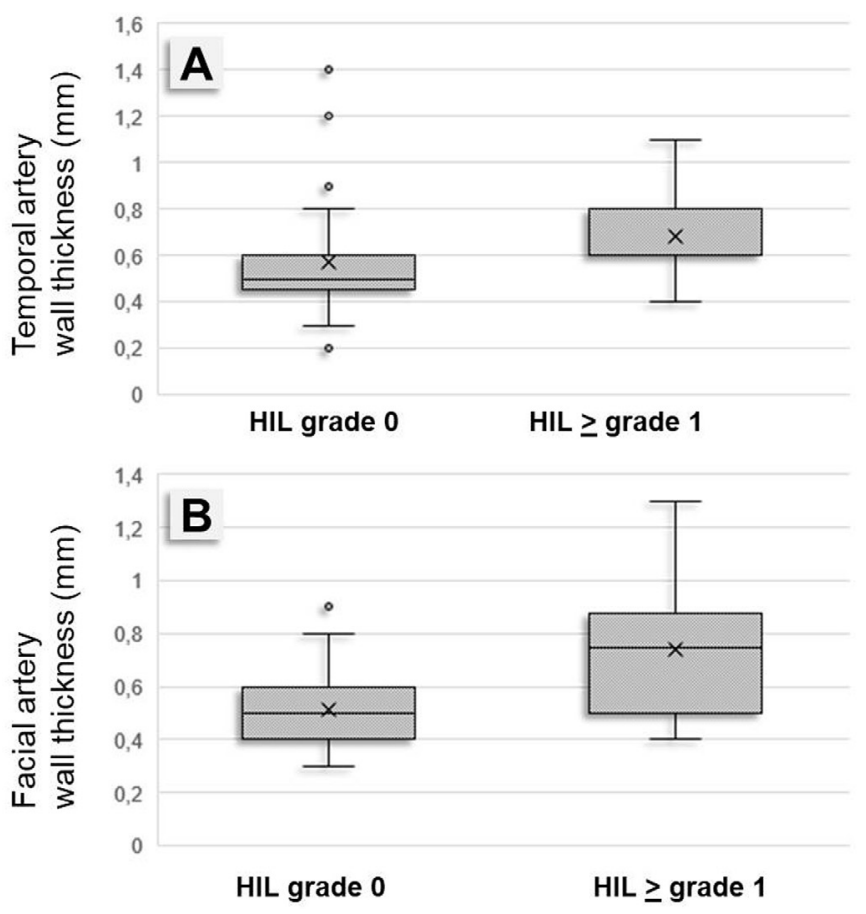

Figure 2 Boxplots of temporal artery wall thickness $(A)$ and facial artery wall thickness $(\mathrm{B})$ in high-resolution $\mathrm{B}$ mode compression sonography, illustrating the comparison between patients with and without HIL in at least one arterial segment. HIL, hyperechogenic intimal lesion.

chronic non-arteritic arterial damage, mainly found in association with advanced age and male sex. The presence of HIL should raise caution when wall thickening of the cranial arteries is found in suspected cGCA (in the presence of HIL almost every second patient had wall thickening above the established cut-off value of $\geq 0.7 \mathrm{~mm}$ in at least one arterial segment). This is particularly true for the facial arteries, which can be easily analysed by HRCS but even more frequently displayed HIL and had a higher maximum wall thickness than the temporal arteries in the present study. These findings have implications with regard to the interpretation of HRCS of the cranial arteries in the diagnostic workup of suspected cGCA. Two studies on individuals without signs and symptoms of cGCA documented rates of approximately $10 \%$ of temporal artery IMT values above the published reference values in subjects considered to be at high or very high cardiovascular risk. ${ }^{710}$ In a recent study, we showed that some male patients above the age of 70 exhibited a temporal artery wall thickness above the established reference values. ${ }^{9}$ Male sex was the only independent predictor of a positive temporal artery ultrasound study in a cohort study of patients with suspected cGCA. In that study, $28 \%$ of patients (mainly men) with a diagnosis other than cGCA had a positive temporal artery ultrasound study. ${ }^{11}$ In an important study by van der Geest $e t$ $a l$, male sex was associated with higher halo counts and halo scores in patients diagnosed with cGCA. This implies that not only the regular IMT but also the vasculitic wall thickening may be more pronounced in men. ${ }^{12}$
Taken together, these results indicate that IMT cut-off values of the cranial arteries for the diagnosis of cGCA need to be refined. According to our results, HRCS cutoff values established for the temporal arteries cannot be applied without constraint for the facial arteries. Our findings contrast with previous studies which found no difference in mean wall thickness between the temporal and facial arteries in healthy controls. ${ }^{3}{ }^{13}$ Future research should be directed towards establishing age-specific and sex-specific as well as cardiovascular-risk adapted reference values of the temporal and facial artery IMT in larger populations. Within this context, HIL may be useful for stratification of IMT measures, provided that sufficient intraobserver and interobserver reliability will be demonstrated in future prospective studies. Diagnostic algorithms including pretest probability, as proposed in the last years by several authors, may be of further value in increasing the positive predictive value of HRCS in the diagnosis of cGCA. ${ }^{12} 14-16$

Some limitations of our study warrant consideration. Only a minority of patients underwent temporal artery biopsy, so that we cannot formally prove the arteriosclerotic nature of the HIL. Lack of temporal artery biopsy also prevented us from applying the American College of Rheumatology classification criteria for cGCA to the overall cohort. ${ }^{17} \mathrm{We}$ instead relied on previously published diagnostic criteria, still awaiting formal validation. ${ }^{39}$ Analysis was restricted to patients with arterial occlusions of the eye, per se representing a cardiovascular high-risk cohort. Review of B-mode sonographic images, depicting only transversal sections at six predefined points of the cranial arteries, may have underestimated the total burden of arteriosclerosis. Arteriosclerotic lesions presenting as focal hypoechoic wall thickening were not considered. The common temporal artery was not included in the analysis, as this vessel segment is more difficult to compress than the temporal artery branches. However, in our previous studies HRCS of the temporal artery branches alone provided high sensitivity for the diagnosis of cGCA. ${ }^{49}$

In summary, our findings add another piece to the puzzle of HRCS of the cranial arteries, linking arteriosclerosis with increased temporal and facial artery wall thickness. These findings should be kept in mind when interpreting cranial artery ultrasound findings in the diagnostic workup of suspected cCGA.

\section{Author affiliations}

${ }^{1}$ Division of Vascular Medicine, Medicial Clinic and Policlinic IV, Hospital of the Ludwig Maximilians University, Munich, Germany

${ }^{2}$ Division of Rheumatology and Clinical Immunology, Medical Clinic and Policlinic IV, Hospital of the Ludwig Maximilians University, Munich, Germany

${ }^{3}$ Department of Ophthalmology, Hospital of the Ludwig Maximilians University, Munich, Germany

${ }^{4}$ Interdisciplinary Sonography Center, Medical Clinic and Policlinic IV, Hospital of the Ludwig Maximilians University, Munich, Germany

Contributors All authors made substantial contributions to the conception or design of the present work, or the acquisition, analysis or interpretation of the included data. All authors were involved in revising the initial draft of the 
manuscript (provided by MC and CL) for important intellectual content. All authors finally approved the submitted version of the manuscript.

Funding The authors have not declared a specific grant for this research from any funding agency in the public, commercial or not-for-profit sectors.

Competing interests None declared.

Patient consent for publication Not applicable.

Ethics approval This is a retrospective study, approved by the local Ethics committee.

Provenance and peer review Not commissioned; externally peer reviewed.

Open access This is an open access article distributed in accordance with the Creative Commons Attribution Non Commercial (CC BY-NC 4.0) license, which permits others to distribute, remix, adapt, build upon this work non-commercially, and license their derivative works on different terms, provided the original work is properly cited, appropriate credit is given, any changes made indicated, and the use is non-commercial. See: http://creativecommons.org/licenses/by-nc/4.0/.

ORCID iDs

Michael Czihal http://orcid.org/0000-0003-4199-6345

Hendrik Schulze-Koops http://orcid.org/0000-0002-1681-491X

\section{REFERENCES}

1 Dejaco C, Ramiro S, Duftner C, et al. EULAR recommendations for the use of imaging in large vessel vasculitis in clinical practice. Ann Rheum Dis 2018;77:636-43.

2 Duftner C, Dejaco C, Sepriano A, et al. Imaging in diagnosis, outcome prediction and monitoring of large vessel vasculitis: a systematic literature review and meta-analysis Informing the EULAR recommendations. RMD Open 2018;4:e000612.

3 Schäfer VS, Juche A, Ramiro S, et al. Ultrasound cut-off values for intima-media thickness of temporal, facial and axillary arteries in giant cell arteritis. Rheumatology 2017;56:1479-83.

4 Czihal M, Schröttle A, Baustel K, et al. B-Mode sonography wall thickness assessment of the temporal and axillary arteries for the diagnosis of giant cell arteritis: a cohort study. Clin Exp Rheumatol 2017;35 Suppl 103:128-33.

5 Sundholm JKM, Pettersson T, Paetau A, et al. Diagnostic performance and utility of very high-resolution ultrasonography in diagnosing giant cell arteritis of the temporal artery. Rheumatol Adv Pract 2019;3:rkz018.

6 Sundholm JKM, Paetau A, Albäck A, et al. Non-invasive vascular very-high resolution ultrasound to quantify artery intima layer thickness: validation of the four-line pattern. Ultrasound Med Biol 2019;45:2010-8.

7 De Miguel E, Beltran LM, Monjo I, et al. Atherosclerosis as a potential pitfall in the diagnosis of giant cell arteritis. Rheumatology 2018;57:318-21.

8 Di Mario C, The SH, Madretsma S, et al. Detection and characterization of vascular lesions by intravascular ultrasound: an in vitro study correlated with histology. J Am Soc Echocardiogr 1992:5:135-46.

9 Czihal M, Köhler A, Lottspeich C. Temporal artery compression sonography for the diagnosis of giant cell arteritis in elderly patients with acute ocular arterial occlusions. Rheumatology 2021;60:keaa515:2196.

10 Martire MV, Cipolletta E, Di Matteo A, et al. Is the intimamedia thickness of temporal and axillary arteries influenced by cardiovascular risk? Rheumatology 2021:keab117.

11 Conway R, O'Neill L, McCarthy GM, et al. Performance characteristics and predictors of temporal artery ultrasound for the diagnosis of giant cell arteritis in routine clinical practice in a prospective cohort. Clin Exp Rheumatol 2019;37 Suppl 117:72-8.

12 van der Geest KSM, Wolfe K, Borg F, et al. Ultrasonographic halo score in giant cell arteritis: association with intimal hyperplasia and ischaemic sight loss. Rheumatology 2020;23:keaa806.

13 Hunder GG, Bloch DA, Michel BA, et al. The american college of rheumatology 1990 criteria for the classification of giant cell arteritis. Arthritis Rheum 1990;33:1122-8.

14 Ing EB, Lahaie Luna G, Toren A, et al. Multivariable prediction model for suspected giant cell arteritis: development and validation. Clin Ophthalmol 2017;11:2031-42.

15 Laskou F, Coath F, Mackie SL, et al. A probability score to aid the diagnosis of suspected giant cell arteritis. Clin Exp Rheumatol 2019;37 Suppl 117:104-8.

16 Czihal M, Lottspeich C, Bernau C, et al. A diagnostic algorithm based on a simple clinical prediction rule for the diagnosis of cranial giant cell arteritis. J Clin Med 2021;10:1163.

17 Ješe R, Rotar Žiga, Tomšič M, et al. The cut-off values for the intima-media complex thickness assessed by colour Dopple sonography in seven cranial and aortic arch arteries. Rheumatology 2021;60:1346-52. 